Tropical Journal of Pharmaceutical Research January 2016; 15 (1): 73-80

ISSN: $1596-5996$ (print); 1596-9827 (electronic)

(C) Pharmacotherapy Group, Faculty of Pharmacy, University of Benin, Benin City, 300001 Nigeria.

All rights reserved.

Available online at http://www.tjpr.org http://dx.doi.org/10.4314/tjpr.v15i1.10

Original Research Article

\title{
Histopathological Effects on Testis of Adult Male Carp, Cyprinus carpio carpio, Following Exposure to Graded Concentrations of Water-Borne Bisphenol A
}

\author{
Amena Ali M Al-Sakran ${ }^{1}$, Promy Virk ${ }^{1 \star}$, Mai Elobeid ${ }^{1}$, Sherifa Shaker Hamed ${ }^{1,3}$, \\ Muzammil Iqbal Siddiqui ${ }^{1}$, Sawsan Omer $^{1}$ and Nada Mohammed Mirghani ${ }^{2}$ \\ ${ }^{1}$ Department of Zoology, King Saud University, PO Box 22452, Riyadh-11495, ${ }^{2}$ Central Lab, King Saud University, Women's \\ Students-Medical Studies \& Sciences Section, Riyadh 11451, Saudi Arabia, ${ }^{3}$ Zoology Department, Faculty of Science, \\ University of Alexandria, Moharram Bey, Alexandria, 21511, Egypt
}

*For correspondence: Email: virkg@hotmail.com; Tel: 09661-0502205785

Received: 15 May 2015

Revised accepted: 29 November 2015

\begin{abstract}
Purpose: To evaluate the estrogenic effect of Bisphenol A (BPA), an endocrine disruptor on the histological features in carp testis

Methods: Adult male fish, koi carp, Cyprinus carpio carpio, were exposed to three graded concentrations of BPA (10, 100 and $1000 \mu \mathrm{g} / \mathrm{L})$ for a period of 21 days. A single dose of $17-\beta$ estradiol $(1 \mathrm{ng} / \mathrm{L})$ was used as positive control. The end points assessed at the end of the exposure period were condition factor, hepatosomatic index (HSI), gonadosomatic index (GSI), histopathological changes in the testis and lobular diameter.

Results: BPA caused a significant decrease in gonadosomatic index (GSI) of the fish at the median concentration of $100 \mathrm{\mu g} / \mathrm{L}$. The major alterations observed in the gonad structure were a significant decrease $(p \leq 0.001)$ in the lobular diameter $(65.1 \pm 12.2 \mu \mathrm{m})$ compared with control $(211.7 \pm 36.60 \mu \mathrm{m})$ and complete loss in lobular structure with degenerating spermatozoa in some carps. The histopathological effects also include delayed sperm maturation and impaired spermatogenesis.

Conclusion: The findings clearly show marked adverse histopathological effects of gonads of adult carps when exposed to BPA.
\end{abstract}

Keywords: Fish, Carp testis, Endocrine disruptors, Bisphenol A, Histopathology, Gonadosomatic index, Sperm maturation, Spermatogenesis

Tropical Journal of Pharmaceutical Research is indexed by Science Citation Index (SciSearch), Scopus, International Pharmaceutical Abstract, Chemical Abstracts, Embase, Index Copernicus, EBSCO, African Index Medicus, JournalSeek, Journal Citation Reports/Science Edition, Directory of Open Access Journals (DOAJ), African Journal Online, Bioline International, Open-J-Gate and Pharmacy Abstracts

\section{INTRODUCTION}

Xenoestrogens are endocrine disrupting chemicals (EDCs) that mimic the natural estrogens and have been reported to cause endocrine disarray in fish and other aquatic organisms [1]. Of all such xenoestrogens registered for use by the Environmental Protection Agency (EPA), the monomer, BPA (2,2-bis-(4-hydroxyphenyl)- propane, an alkyl phenol has perhaps triggered the greatest amount of interest among researchers and its use has been a debatable issue during the past decade[2]. While the point sources of BPA in the environment are sewage effluent and landfill leachate, fragments of epoxy resins and polycarbonate plastic debris entering the watershed through runoff make up the non-point sources [3]. The ubiquity of BPA in the aquatic environment is well established [4], with BPA accumulating in water systems from anthropogenic sources [2]. 
The estrogenic potency of BPA is well documented [2,5-8]. Effects of endocrine disrupting chemicals like BPA on fish are evaluated by gross gonad morphology and histology [6,7]. Since exogenous estrogens have the potential to interfere with the sexual development and reproduction of aquatic vertebrates [9], reproductive ability is a sensitive indicator of stress induced by these compounds. Thus an evaluation of reproductive dysfunction based on gonad morphology and spermatogenic endpoints are ideal biomarkers.

The present study was aimed at assessing and understanding the deleterious alterations in the testes of sexually mature cyprinid, Koi carp Cyprinus carpio carpio exposed to graded concentrations of Bisphenol A (BPA) for 21 days. The key endpoints assessed at the end of the exposure period were the somatic parameters and histopathology of the testis.

\section{EXPERIMENTAL}

\section{Preparation of fish}

One year-old mature male koi carp Cyprinus carpio carpio ( $\mathrm{n}=60$, mean body mass $=150$ $200 \mathrm{~g}$, and mean body length $=22 \mathrm{~cm}$ ) were obtained from a local fish farm near Riyadh city in October 2012 and were divided into six exposure groups of 10 fish each. Prior to the experimental period the fish were acclimatized to laboratory conditions in glass aquaria for 15 days. During this period, each glass aquarium was filled with $100 \mathrm{~L}$ of aerated and dechlorinated tap water. Natural 12 h light: $12 \mathrm{~h}$ dark schedule was maintained. Temperature was maintained between $24-26{ }^{\circ} \mathrm{C}$ and dissolved oxygen was at least $90 \%$ saturation at all times. During the acclimatization and exposure period, fish were fed a commercial diet of dry pellet feed at $1 \%$ body weight per day. All animal procedures were performed in accordance with the standards set forth in the Guidelines for the Care and Use of Experimental Animals by the Committee for the Purpose of Control and Supervision of Experiments on Animals (CPCSEA) [10].The study protocol was approved by the Animal Ethics Committee of the Zoology Department, College of Science of King Saud University, Saudi Arabia (approval no. 799432).

\section{BPA exposure}

Following acclimatization the fish were exposed to different water-borne concentrations of BPA $(10,100,1000 \mu \mathrm{g} / \mathrm{L})$ for 21 days.
Analytical grade BPA (CAS Registry no. 80-05-7, $98 \%$, Lobachemie, India) was used as the test xenoestrogen and 17 $\beta$-Estradiol (E2) (97\%, Lobachemie, India) was used as a positive control. Stock solutions of both the chemicals were prepared in acetone $(99.5 \%$, Schartab S.L, Spain).The stock solutions were used to prepare the three dosing test solutions with nominal concentrations of $\operatorname{BPA}(10,100,1000 \mu \mathrm{g} / \mathrm{L})$ and one test solution with nominal concentration of E2 (1 ng/L). The two remaining glass aquarium were negative controls, one receiving only dechlorinated tap water while the other was the vehicle (acetone) as control.

During the exposure period, the water, BPA, E2 and acetone of each glass aquarium were changed after 7 days and the physico-chemical parameters of water were analyzed at regular intervals and were in the conducive range. There was no mortality during the exposure period. After 21 days of exposure seven fish from each group were taken out and anaesthetized. Body mass (nearest gram) and the body length (nearest $\mathrm{mm}$ ) of each fish was recorded. The fish were subsequently sacrificed, the liver and gonads excised and weighed separately to assess the hepatosomatic index (HSI) and gonadosomatic index (GSI). Condition Factor (K), HSI and GSI were calculated as in Eqs 1 3 , respectively [11-12]:

$\mathrm{K}=\mathrm{W} / \mathrm{L}^{3}$

where $\mathrm{W}=$ weight of fish and $\mathrm{L}=$ length of fish.

$\mathrm{HSI}=(\mathrm{Lm} / \mathrm{Bm}) 100)$

$\mathrm{GSI}=/[\mathrm{Gm} / \mathrm{Bm}) 100$.

where $\mathrm{Gm}$ is gonad mass.

\section{Histological techniques and photomicro- graphy}

Samples of fragments of fresh testes were fixed in $10 \%$ buffered formalin. Sections of the testes were taken from the apical portion for all groups. Thereafter the tissues were dehydrated through a graded series of ethanol (from 70 to $100 \%$ ethanol in subsequent steps). Xylene was used as a clearing agent. Tissues were embedded in paraffin $\left(58.6^{\circ} \mathrm{C}\right)$. Sections $(5 \mu \mathrm{m})$ were stained with haematoxylin and eosin, and were examined and photographed using a photomicroscope. Stages of spermatogenesis were determined according to the germ cell types present and their relative abundance [13]. The histopathological alterations were assessed on 
reduction of average lobule diameter and alterations in the germ cell types.

\section{Determination of lobular diameter}

The average diameter of the seminiferous lobules was measured using a calibrated ocular scale by randomly selecting twenty lobules of comparable shape per gonad.

\section{Statistical analysis}

Since the data in control and solvent control showed no significant difference, they were pooled together. All presented data are expressed as mean values \pm standard deviation (SD). Group differences were analyzed with unpaired Student's t-test. Numerical data was correlated with SPSS 16.0 statistical software (Chicago, IL, USA). The level of significance was set at $p \leq 0.05$.

\section{RESULTS}

Exposure to the BPA and the E2 at levels employed in the present study did not cause any mortality nor did it affect the growth of the fish as there was no significant difference in the condition factor of fish from all the experimental groups post exposure (Fig. 2). Distinct anatomical anomalies were observed in the testes of carps exposed to $100 \mu \mathrm{g} / \mathrm{L}$ of BPA (Fig $1 \mathrm{~b}, \mathrm{c}$ ) in comparison to those from the control group (Fig 1a).

Marked histopathological alterations were observed in the testes of carps exposed to the low doses of BPA (10 and $100 \mu \mathrm{g} / \mathrm{L}$ ) and E2 (positive control) in comparison to the control group.

\section{Somatic parameters}

There was no significant difference observed in the Condition factor and Hepatosomatic Index of carps in the control and the treated groups. However, a significant decrease $(p \leq 0.01)$ in the GSI was observed in the group exposed to 100 $\mu \mathrm{g} / \mathrm{L}$ of BPA (1.8) in comparison to the control (5.9). The GSI of carps in other treated groups did not vary significantly from the control (Fig 2).

\section{Diameter of seminiferous lobules}

Testes of carps in all the treated groups showed a statistically significant $(p \leq 0.001)$ decrease in the lobular diameter in comparison to the control $(211.7 \pm 36.59 \mu \mathrm{m})$ being marked in the group exposed to $100 \mu \mathrm{g} / \mathrm{L}$ BPA $(65.1 \pm 12.15 \mu \mathrm{m})$ followed by the positive control group exposed to $1 \mathrm{ng} / \mathrm{L}$ E2 (100.6 $\pm 17.77 \mu \mathrm{m})$ (Fig 3).
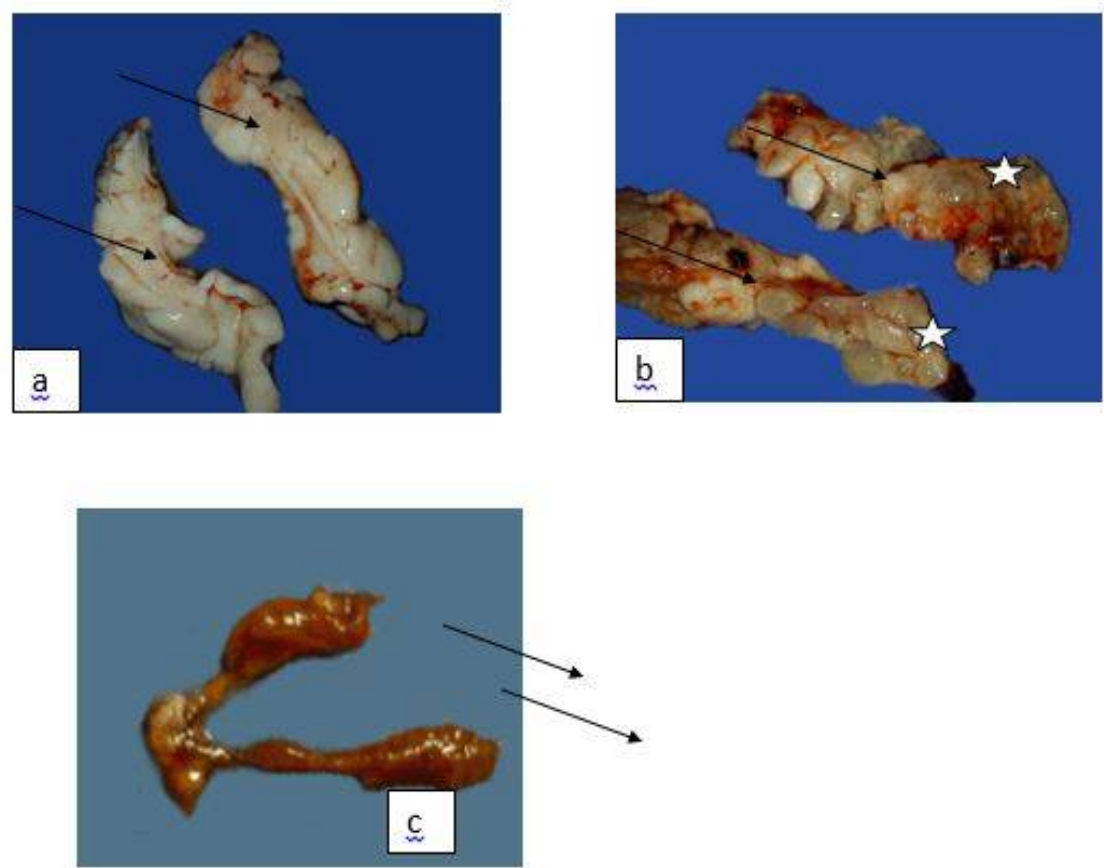

Fig 1: Gross anatomy of Carp Testis; (a) Normal mature testis from the Control group. Anomalies observed in the testis of carps exposed to $100 \mu \mathrm{g} / \mathrm{L}$ of BPA; (b) Notice the puffiness observed (star); (c) A highly reduced testicular size, notice the change in coloration (arrows) 


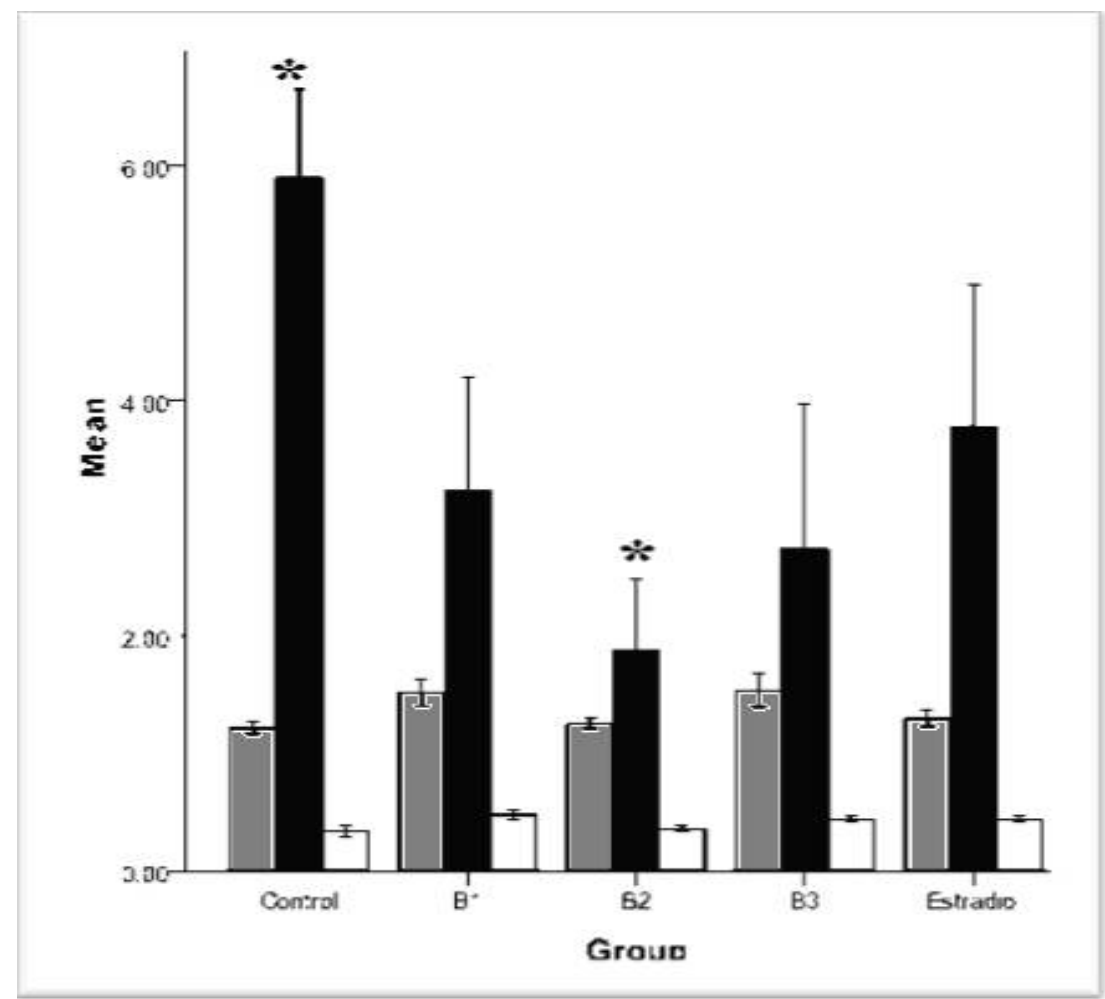

condition factor gonadosomatic index hepatosomatic index

Fig 2: Condition factor(K), gonadosomatic Index (GSI), hepatosomatic index (HSI) (mean $\pm \mathrm{SD}$ ) of carps exposed to the three concentrations of BPA, $10 \mu \mathrm{g} / \mathrm{L}$ (B1), $100 \mu \mathrm{g} / \mathrm{L}$ (B2), $1000 \mu \mathrm{g} / \mathrm{L}$ (B3), positive control (E2) and negative control; ${ }^{*} p \leq 0.05$

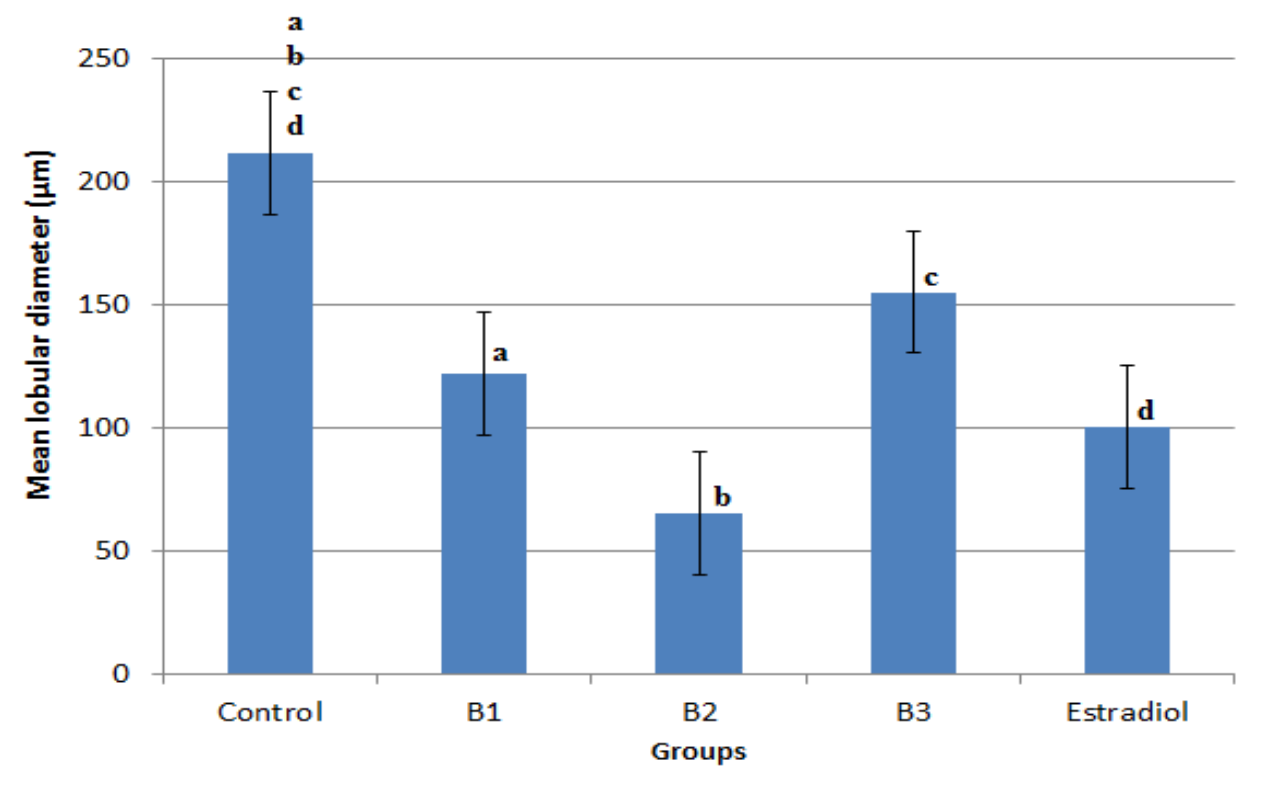

Fig 3: Mean \pm SD diameter of the seminiferous lobules $(\mu \mathrm{m})$ in the histological sections of the carps testes exposed to the three concentrations of BPA, $10 \mu \mathrm{g} / \mathrm{L}$ (B1), $100 \mu \mathrm{g} / \mathrm{L}$ (B2), $1000 \mu \mathrm{g} / \mathrm{L}$ (B3), positive control (E2) and control. Different letters indicate significant differences between groups $(p \leq 0.05)$. All treated groups are highly significantly different from control $(p \leq 0.001)$ 


\section{Histopathology of testis}

The testes of the control fish showed the typical organization of the carp testis with large seminiferous lobules (SL) and the interlobular spaces with interstitial cells and blood vessels. The two stages of maturity exhibited in the testis were mainly the spermiation stage, with free spermatozoa (SPZ) filled in the lobular lumen and active spermatogenesis characterized by spermatogenic cysts (SC) (Fig 4 a).

Starting from the lowest concentration of $10 \mu \mathrm{g} / \mathrm{L}$ of BPA, the exposed fish showed a decreased lobular diameter (Fig 2). Although there was noalteration in the lobular structure a decreased intensity in the mature free SPZ in the lobular lumen was observed in the sections of testes of carps exposed to $10 \mu \mathrm{g} / \mathrm{L}$ of BPA. This reflected a delayed maturation as more number of spermatogonia (SPG) and spermatocytes (SPC) were observed in the lobules (Fig 4b). A few sections of the carp testis exposed to the same concentration showed the presence of developmental stages of oocytes associated with the testicular tissue (Fig 4c and d). At a higher concentration of $100 \mu \mathrm{g} / \mathrm{L}$ pronounced testicular atrophy was observed in some exposed fish. This was characterized by a loss of lobular organization, presence of lacunae with disintegration of the germinal epithelium. A few distorted lobules showed residual germ cells and SPG (Fig 5a). Other carps exposed to the same concentration $(100 \mu \mathrm{g} / \mathrm{L})$ showed a significantly reduced lobular size with lacunae and SPG with a few primary oocytes (Figs. $5 \mathrm{~b}$ and c). Overall, the effect observed indicates inhibition of spermatogenesis and loss of testicular organization.

At the highest concentration of BPA $(1000 \mu \mathrm{g} / \mathrm{L})$, the exposed fish did not show any alteration in the lobular structure. The testicular organization was intact comparable to the control with advanced stage of spermatogenesis characterized by the presence of SC and SPZ. However the lobular diameter was reduced (Fig. $5 d$ ). The testis of the carps exposed to $1 \mathrm{ng} / \mathrm{L} \mathrm{E2}$ (positive control) showed a regressed testis with diminished lobular size. Spermatogenesis was inhibited with residual SPZ in the lobular lumen. The lobules had vacuolar spaces with increased amorphous matrix in the interlobular space. The effects are comparable to the most affected group of carps exposed to $100 \mu \mathrm{g} / \mathrm{L}$ of BPA (Figs 5 e and $f)$.
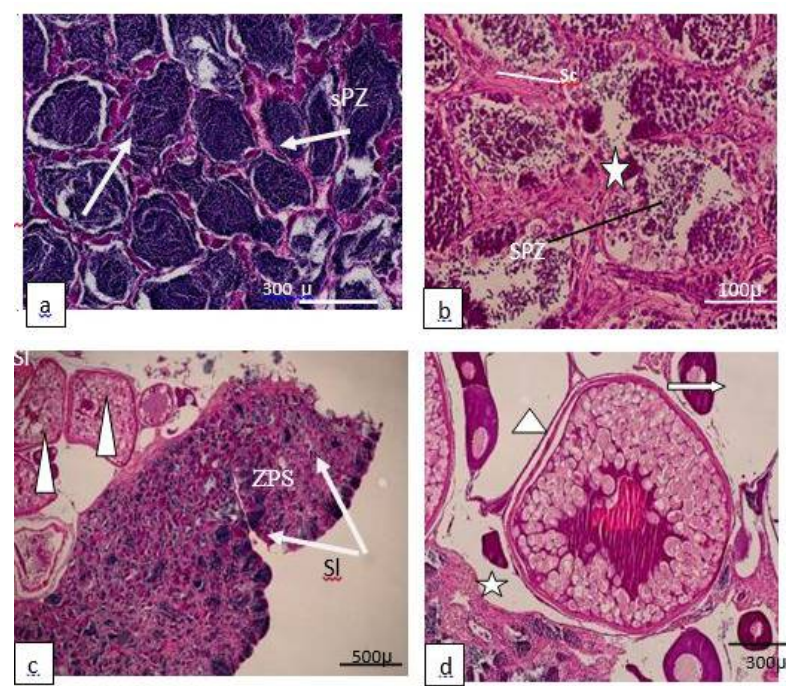

Fig 4: Photomicrographs of transverse sections of $C$. carpio carpio males from the control group and the group exposed to $10 \mu \mathrm{g} / \mathrm{L}$ of BPA. a) Testis (20x) of the control group with seminiferous lobules (SI) filled with spermatozoa (SPZ). b) Testis (40x) of carp exposed to $10 \mu \mathrm{g} / \mathrm{L}$ of BPA. Notice atrophy of seminiferous tubules (SI); a slight decrease in lobular diameter and increased perilobular connective tissue (star). c) Testis (20x) of carp exposed to $10 \mu \mathrm{g} / \mathrm{L}$ of BPA showing different stages of oocytes (arrowheads) in contact with the testis with seminiferous lobules (SI). d) Higher magnification (100x) of the previous histological section focusing on the oocytes at different developmental stages. Notice Testis section (star), Vitellogenic stage of oocyte (arrowhead), Previtellogenic stage of oocyte (arrows).

\section{DISCUSSION}

The endocrine disruptive nature of BPA which impairs reproductive physiology has been extensively reviewed in the past based on comparative studies both in mammals and fish [8]. There is a great deal of evidence that in vivo experimental exposure of adult male fish to BPA has detrimental effects on the gonadal morphology and histology. A few studies that can be cited with their findings are decreased spermatozoa and abnormal testicular connective tissue in Japanese medaka Oryzias latipes [15], reduced GSI and inhibition of spermatogenesis in fathead minnow Pimephales promelas [6], loss of testicular structure and increase in fibrotic tissue and decrease in number of spermatozoa in Japanese medaka Oryzias latipes [16], adverse effect on sperm quality in brown trout Salmo trutta fario [17], impaired steroidogenesis and altered gonad histology in adult common carp Cyprinus carpio [7], and impaired steroidogenesis and sperm quality, in goldfish Carassius auratus L [8].

The decrease in testicular weight of male fish with exposure to estrogenic chemicals has 

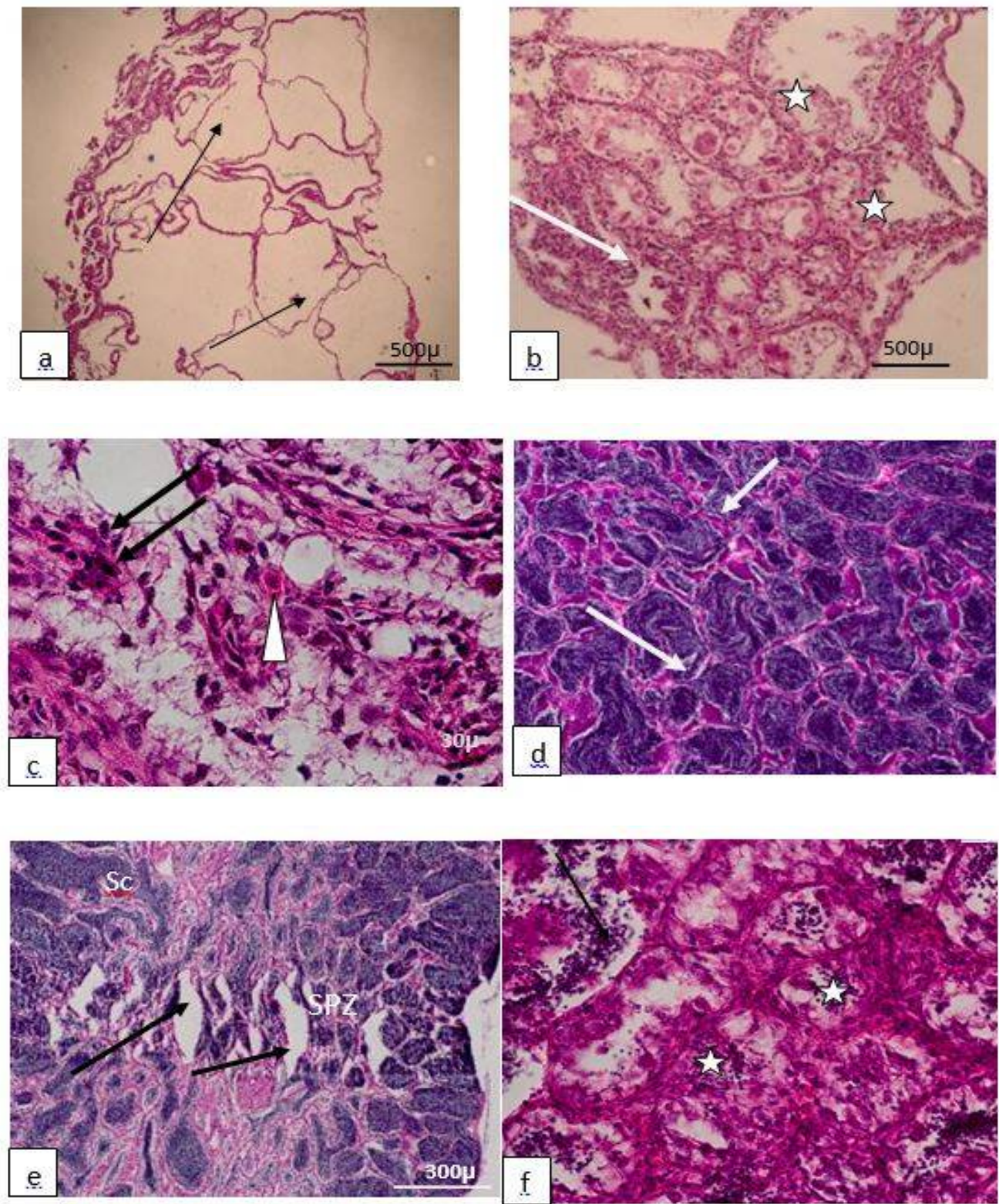

Fig 5: Photomicrographs of transverse sections of $C$. carpio carpio males from the groups exposed to $100 \mu \mathrm{g} / \mathrm{L}$, $1000 \mu \mathrm{g} / \mathrm{L}$ of BPA and $1 \mathrm{ng} / \mathrm{L}$ of E2. a) Testis (20x) of carp exposed to $100 \mu \mathrm{g} / \mathrm{L}$ of BPA demonstrating acute testicular atrophy and vacuolated seminiferous lobules (arrows). b)Testis (40x) of another carp exposed to the same concentration, $100 \mu \mathrm{g} / \mathrm{L}$ of BPA showing reduced lobular diameter, disintegration of the lobular structure(star), few residual spermatogonia(SPG)(arrows). c) Testis (100x) of carp exposed to $100 \mu \mathrm{g} / \mathrm{L}$ of BPA showing pyknotic spermatogonia (arrows); presence of oogonia within the seminiferous lobules (arrowheads). d) Testis (20x) of carp exposed to $1000 \mu \mathrm{g} / \mathrm{L}$ of BPA showing testicular organization; slightly reduced lobular diameter; spermatozoa(SPZ); spermatogenic cysts (SC). e) Testis (20x) of carp exposed to $1 \mathrm{ng} / \mathrm{L}$ of E2 showing reduced lobular diameter; degeneration of seminiferous lobules (arrows). f) Higher magnification (40x) of the testis of carp exposed to the $1 \mathrm{ng} / \mathrm{L}$ of E2 showing residual spermatogonia (arrows), distorted lobular structure (SI) and degenerating germinal epithelium (star)

established the GSI as a biomarker of aquatic wildlife to environmental estrogenic chemicals [18]. Reduced GSI has been reported in male fish exposed to the natural female steroidal hormones, estradiol [19], biodegradates of detergents like nonylphenol and octylphenol [20] and other alkylphenols like BPA [6]. In polluted river waters the synergestic effect of estrogenic EDCs like estradiol (E2), nonylphenol, oroctylphenol $[18,20]$ showed a decrease in GSI of common carps. Although Mandich et al [7] did not observe any significant changes in both GSI and $\mathrm{HSI}$ of mature male carps exposed to BPA concentrations of 1-1000 $\mu \mathrm{g} / \mathrm{L}$, our study showed 
a pronounced and significant decrease in the $\mathrm{GSI}$ of carps exposed to BPA $(100 \mu \mathrm{g} / \mathrm{L})$ which is concomitant to the testicular atrophy observed at this concentration. This was evident with the reduced number of viable spermatozoa and the presence of residual spermatozoa in the lumen of the testes exposed to $100 \mu \mathrm{g} / \mathrm{L}$ of BPA.

The results of our study demonstrate gonadal disarray at all concentrations of BPA (10 - 1000 $\mu \mathrm{g} / \mathrm{L})$ being more pronounced at $100 \mu \mathrm{g} / \mathrm{L}$ which was comparable to the positive control $(1 \mathrm{ng} / \mathrm{L}$ E2) group. The major effects were a significant decrease in the GSI, decreased lobular diameter, loss of testicular architecture and impaired spermatogenesis. Previous studies have also focused on similar tissue-level endpoints $[6,7,16]$, however the effects are variable at low and high doses of BPA. In our study, there was a progressive decrease in lobular diameter and number of spermatogenetic cysts in groups exposed to 10 and $100 \mu \mathrm{g} / \mathrm{L}$ of BPA. Further, a corresponding increase in testicular atrophy was also observed in these groups. Presence of testicular oocytes were observed in carps exposed to a median concentration $(100 \mu \mathrm{g} / \mathrm{L})$ of BPA, while the highest concentration $(1000 \mu \mathrm{g} / \mathrm{L})$ showed less adverse effects on the carp testis. This is in line with the findings of a study by Metcalfe et al [16], where an exposure to low concentrations $\geq 50 \mu \mathrm{g} / \mathrm{L}$ of BPA for 100 days on male Oryzias latipes, showed a loss of cellular organization with increased interstitial spaces in the testis. The presence of both previtellogenic and vitellogenic oocytes associated with the testicular tissue were observed in a few carps exposed to the lowest concentration of BPA $(10 \mu \mathrm{g} / \mathrm{L})$. This condition however cannot be extrapolated as ovotestis as the sample size showing this condition was small. However, it is a morphological anomaly in the gonad and was not observed in the carps from the control group.

The testicular dysfunction caused by the exposure to BPA both at an environmentally relevant concentration $(10 \mu \mathrm{g} / \mathrm{L})$ and at higher concentrations $(100$ and $1000 \mu \mathrm{g} / \mathrm{L})$ in the present study were comparable to the effect of the E2 (1 ng/L).This could be possibly attributed to the mild estrogenic potency of BPA [6]. This further explains the fact that BPA does impair steroidogenesis [7] in exposed males. .

Our results on the effects of the three doses of BPA on testicular structure demonstrate an inverted U-shaped dose-effect curve" (IUSDEC), which is a nonlinear relationship. A commentary on the extensively reviewed literature on lowdose effect of BPA by vom Saal and Hughes [21] clearly states the importance of an inverted-U dose-response phenomenon in studies of chemicals such as BPA which is relevant for assessing the possibility of unique effects that only occur within a specific low-dose range. This plausibly supports our findings which did not reflect a dose-dependent response as the highest dose of BPA $(1000 \mu \mathrm{g} / \mathrm{L})$ showed minimal alterations as compared to the adverse effects observed at low $(10 \mu \mathrm{g} / \mathrm{L})$ dose and more marked at the median $(100 \mu \mathrm{g} / \mathrm{L})$ dose.

\section{CONCLUSION}

Exposure to BPA did affect testicular growth, impaired spermatogenesis and caused deleterious histopathological alterations in the testis and hepatic tissues. Although a concentration of $100 \mu \mathrm{g} / \mathrm{L}$ of BPA had a more profound effect on the testis, a lower but an environmentally realistic concentration of $10 \mu \mathrm{g} / \mathrm{L}$ also elicited detectable adverse effects on testicular morphology and physiology.

\section{ACKNOWLEDGEMENT}

This research project was supported by a grant from the "Research Center of the Female Scientific and Medical Colleges", Deanship of Scientific Research, King Saud University, Riyadh, Saudi Arabia.

\section{REFERENCES}

1. Arukwe A, Knudsen FR, Goksøyr A. Fish zona radiata (Eggshell) protein: $A$ sensitive biomarker for environmental estrogens. - Environ Health Perspect.1997; 105: 418-422.

2. Flint S, Markle T, Thompson S, Wallace E. Bisphenol A exposure, effects, and policy: $A$ wildlife perspective. $J$ Environ Manag 2012; 104:19-34.

3. Crain $D A$, Eriksen $M$, Iguchi $T$, Jobling $S$, Laufer $H$, LeBlanc GA, Guillette LJ (Jr). An ecological assessment of bisphenol-A: Evidence from comparative biology. Reprod Toxicol 2007; 24: 225-239.

4. Vethaak $A D$, Lahr J, Schrap SM, Belfroid AC, Rijs GBJ, Gerritsen $A$, de Boer J, Bulder ,AS, Grinwis GCM, Kuiper $R V$,et al.. An integrated assessment of estrogenic contamination and biological effects in the aquatic environment of The Netherlands. Chemosphere. 2005; 59: 511-524.

5. Toppari J, Larsen J, Christiansen $P$, Giwercman A, Grandjean $P$, Guillette Jr. LJ, Jégou B, Jensen TK, Jouannet $P$, Keiding $N$, et al. Male reproductive health and environmental xenoestrogens. Environ Health Perspect1995; 104(4): 741-803.

6. Sohoni P, Tyler CR, Hurd K, Caunter J, Hetheridge M, Williams $T$, Woods $C$, Evans $M$, Toy $R$, Gargas $M$, Sumpter JP. Reproductive effects of long-term exposure 
to bisphenol $A$ in the fathead minnow (Pimephales promelas). Environ Sci Technol 2001; 35: 2917-2925.

7. Mandich A, Bottero S, Benfenati E, Cevasco A, Erratico $C$, Maggioni S, Massari A, Pedemonte F, Viganò L. In vivo exposure of carp to graded concentrations of bisphenol A. Gen Comp Endocrinol 2007; 153: 15-24.

8. Hatef A, Mohammad Hadi Alavi S, Abdulfatah A, Fontaine $P$, Rodina $M$, Linhart $O$. Adverse effects of bisphenol $A$ on reproductive physiology in male goldfish at environmentally relevant concentrations. Ecotoxicol. Environ. Safety 2012; 76: 56-62.

9. Colborn T, vom Saal FS, Soto AM. Developmental effects of endocrine-disrupting chemicals in wildlife and humans. Environ Health Perspect1993; 101: 378-384.

10. Guidelines for the Care and Use of Experimental Animals by the Committee for the Purpose of Control and Supervision of Experiments on Animals (CPCSEA). http://icmr.nic.in/bioethics/final_cpcsea.pdf

11. Ricker WE. Computation and interpretation of biological statistics of fish populations. B Fish Res Board Can 1975; 191: 1-382.

12. Werner J, Wautier K, Evans RE, Baron CL, Kidd $K$, Palace V. Waterborne ethynyl estradiol induces vitellogenin and alters metallothionein expression in lake trout (Salvelinus namaycush). Aquat Toxicol 2003; 62 . 321-328.

13. Panter BN, Sumpter JP, Thompson RS. Transformation of a non-oestrogenic steroid metabolite to an oestrogenically active substance by minimal bacterial activity. Chemosphere 1999; 38:3579- 3596.

14. Goodbred SL, Gillion RJ, Gross TS, Denslow NP, Bryant WL, Schoeb TR. Reconnaissance of 17- $\beta$ estradiol, 11-ketotestosterone, vitellogenin, and gonad histopathology in common carp of United States streams: potential for contaminant-induced endocrine disruption: U.S. Geological Survey Open-File Report 1997; 96-627, pp 1-47.

15. Yokota H, Tsuruda Y, Maeda M. Effect of bisphenol A on the early life stage in Japanese medaka (Oryzias latipes). Environ Toxicol Chem 2000; 19(7):1925-1930.

16. Metcalfe $C D$, Metcalfe TL, Kiparissis Y. Estrogenic potency of chemicals detected in sewage treatment plant effluents as determined by in vitro assays with Japanese medaka (Oryzias latipes). Environ Toxicol Chem. 2001; 20: 297-308.

17. Lahnsteiner F, Berger B, Kletzl M. Effect of Bisphenol A on maturation and quality of semen and eggs in the brown trout, Salmo trutta f. fario. Aquat Toxicol 2005; 75: 213-224.

18. Hassanin A, Kuwahara S, Nurhidayat, Tsukamoto $Y$, Gonadosomatic Index and testis morphology of common carp (Cyprinus carpio) in rivers contaminated with estrogenic chemicals. J Vet Med Sci 2002; 64: 921-926.

19. Nimrod AC, Benson WH. Reproduction and development of Japanese medaka following an early life stage exposure to xenoestrogens. Aquat Toxicol.1998; 44:141-156.

20. Patino R, Goodbred SL, Draugelis-Dale R. Morphometric and histopathological parameters of gonadal development in adult common carp from contaminated and reference sites in Lake Mead Nevada. J Aquat Anim Health 2003; 15:55-68.

21. vom Saal FS, Hughes C. An extensive new literature concerning low-dose effects of bisphenol $A$ shows the need for a new risk assessment. Environ Health Perspect 2005; 113: 926-933. 